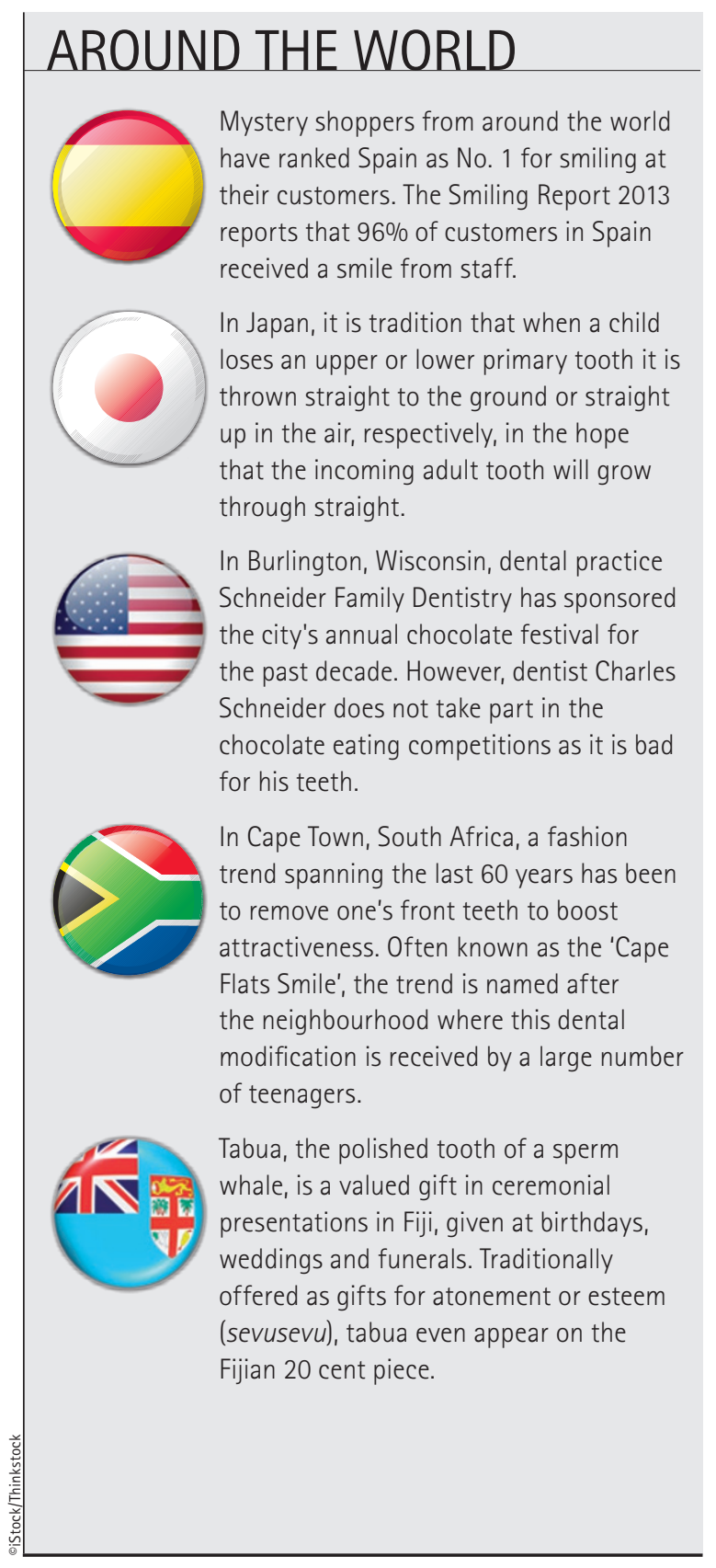

IN THIS ISSUE In this issue Assistant Editor Laura

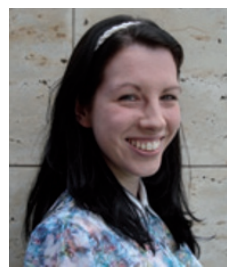
Pacey writes on the effect of the growing number of women in the dentistry workforce.

Laura is our resident "prehistoric' dentistry news writer, having proved fond of reporting tales of fossilised animal teeth and Neanderthal diets.

Laura is a North London girl who joined the $B D J$ editorial team in late 2011 after reading classics at the University of Warwick. In her two years on the team, she admits to having become obsessed with $B D J$ house style, and wants to edit everything she sees!

Did you know? Laura's favourite cocktail is the Kir Royale. She has an identical twin sister called Jessica.

\title{
INVESTIGATION
}

\section{HAVE WOMEN CHANGED THE DENTAL WORKFORCE?}

$\mathrm{J}$ ames Brown claimed it's a man's world, but with the number of female dental professionals rising rapidly, it is estimated that over half of all UK dentists will be women by 2020 . This raises questions over what this might mean for workforce planning and whether women really can 'have it all', balancing a family and professional life with minimal impact to dental services.

This issue is not new; at the start of the millennium Dame Margaret Seward discussed the increasing number of women in the dental workforce and its potential effects in this Journal, ${ }^{1}$ but in the last five years alone the percentage of female dentists has risen by $5 \%$ and, as over $50 \%$ of dental students are now female, this trend is set to continue. The majority of dentists under the age of 35 are female (55.4\%, 2011/12) while over $90 \%$ of dentists over 65 are male; ${ }^{2}$ thus the greater proportion of dentists leaving the profession over the coming years will be men, while women continue to enter the workforce at a higher rate.

Despite this increase there are only two dental specialties where females hold the larger percentage of positions: paediatrics and

'In many ways it is up to female dentists to shape their own future, actively engaging in and contributing to the dental community' special care dentistry, while historically male-dominated roles such as oral surgery still retain a higher percentage of men at $72.8 \% .^{3}$ This presents a problem, as Judith Husband, Chair of the BDA Education, Ethics and the Dental Team Working Group, argues: 'Without women in senior leadership positions throughout dentistry, it will be difficult to engage the full profession [in shaping dentistry] and a divided group is never as strong as when unified by common goals and interests.'

Yet the fact remains that male dentists currently contribute more working hours across their career and generally have fewer career breaks than females. ${ }^{4}$ Thus it is perhaps understandable that men hold more senior positions than their female counterparts. It must be noted, however, that the difference between genders in working hours is minimal pre-career breaks. Women are more likely to reduce their hours upon returning to work following a career break and the difference in hours worked between a female dentist that has and has not taken a break across a working lifespan is about $15,000 .{ }^{4} \mathrm{In}$ their 2001 study, Newton et al. ${ }^{5}$ found that $61 \%$ of female dental practitioners had taken a career break at some point in their lives, whereas only 27\% of male dentists had. Assuming that over half of female dentists under the age of 35 will take time out of their career to have children, this could lead to a shortage of dentists in the near future. Will policy change to alleviate any shortfall during women's child bearing years? Professor Tim Newton suggests 'If we wish to 